\title{
\begin{tabular}{l|l|l} 
& Jurnal Kependidikan Dasar & $\begin{array}{l}\text { Volume : } 2 \\
\text { Nomor : } 2\end{array}$ \\
Tahun : 2017
\end{tabular}
}

\section{Pengembangan Media Audio Visual Mata Pelajaran Bahasa Indonesia Untuk Sekolah Dasar}

\author{
Friendha Yuanta \\ Universitas Wijaya Kusuma Surabaya \\ Surel : www.friendha@gmail.com
}

\begin{abstract}
Abstrak
Bahasa Indonesia merupakan salah satu mata pelajaran yang diajarkan di sekolah dasar. Salah satu kegiatan berbahasa adalah menyimak. Berdasarkan hasil pengamatan diketahui bahwa pembelajaran Bahasa Indonesia pada ketrampilan menyimak cerita belum berjalan secara optimal. Hal ini dapat dilihat dari setiap pembelajaran guru masih menggunakan metode ceramah. Sehingga siswa terlihat kurang antusias dan cenderung pasif. Penggunaan media audio visual dalam pembelajaran diharapkan adanya peningkatan dalam proses pembelajaran, terutama dalam hal menyimak cerita. Kegiatan pengembangan ini dilaksanakan dengan tujuan menghasilkan media audio visual mata pelajaran Bahasa Indonesia kelas 3 semester 2 yang efektif, membuat siswa dapat menerima pembelajaran dengan baik. Metode yang digunakan dalam pengembangan ini menggunakan model Dick and Carey. Model ini memiliki sepuluh langkah prosedural, hanya saja untuk pengembangan ini diadaptasi menjadi sembilan langkah, yakni: (1) mengidentifikasi tujuan umum pembelajaran (2) analisis pembelajaran (3) mengidentifikasi karakteristik siswa (4) merumuskan tujuan khusus pembelajaran (5) mengembangkan instrumen penilaian (6) mengembangkan strategi pembelajaran (7) mengembangkan dan memilih bahan pembelajaran (8) merancang dan melaksanakan evaluasi formatif (9) merevisi produk pembelajaran. Hasil akhir yang diperoleh dari pengembangan media audio visual ini adalah produk yang dikembangkan termasuk dalam kriteria valid/layak untuk digunakan dalam proses pembelajaran.
\end{abstract}

Kata Kunci : Pengembangan, media audio visual, Bahasa Indonesia

\begin{abstract}
Bahasa Indonesia is one of the subjects taught in elementary school. One of the language activities is listening. Based on the observation, it is known that the learning of Bahasa Indonesia in listening skill of the story has not run optimally yet. This can be seen from each teacher's learning still using the lecture method. So the students look less enthusiastic and tend to be passive. The use of audio-visual media in learning is expected to increase in the learning process, especially in terms of listening to the story. This development activity is carried out with the aim of producing an audio visual media of Indonesian class 3 semester 2 that is effective, enabling the students to receive learning well. The methods used in this development use the Dick and Carey model. This model has ten procedural steps, only for this development is adapted into nine steps, namely: (1) identify the general objectives of learning (2) learning analysis (3) identify the characteristics of students (4) formulate specific objectives of learning (5) develop assessment instruments (6) developing learning strategies (7) developing and selecting learning materials (8) designing and executing formative evaluations (9) revising learning products. The end result obtained from the development of this audio visual media is developed products included in the criteria valid / eligible to be used in the learning process.
\end{abstract}

Keywords : Development, audio visual media, Bahasa Indonesia 


\section{A. PENDAHULUAN}

Perkembangan teknologi dan ilmu pengetahuan yang sangat pesat, khususnya teknologi informasi sangat berpengaruh terhadap penyusunan dan penerapan strategi pembelajaran. Melalui perkembangan teknologi dan ilmu pengetahuan tersebut para guru dapat menggunakan berbagai media sesuai dengan kebutuhan dan tujuan pembelajaran. Media dapat meningkatkan produktivitas pendi-dikan. ${ }^{1}$

Salah satu bentuk media komunikasi elektronik adalah media audio-visual. Misalnya media video dengan karakteristik utamanya "visual motion" serta dukungan audio. Penggunaan media video (audio-visual) sebagai sumber belajar, dapat dilakukan dengan dua cara, (1) by utilization yaitu memanfaatkan produk yang pada awalnya tidak dirancang untuk pembelajaran, (2) by design artinya media tersebut dirancang/ dikem-bangkan berdasarkan tujuan pembelajaran tertentu sehingga keberadaanya merupakan bagian integral dari sistem pembelajaran. Oleh sebab itu fungsi utama dari media pembelajaran ini adalah sebagi alat bantu belajar mengajar yang dipergunakan oleh guru.

Bahasa Indonesia merupakan salah satu dari sekian banyak mata pelajaran yang diajarkan di sekolah dasar. Salah satu kegiatan berbahasa adalah menyimak yang mempunyai urgensi tinggi untuk memperoleh ketrampilan

${ }^{1}$ Punaji Setyosari dan Sihkabuden, Media Pembelajaran (Malang: Elang Mas, 2005). yang lain. Pada umumnya setiap hari orang menggunakan waktu komunikasinya 45\%, mendengarkan $30 \%$, bicara $16 \%$, membaca $16 \%$ dan menulis $9 \% .^{2}$

Berdasarkan hasil pengamatan di lapangan diketahui bahwa pem-belajaran Bahasa Indonesia pada ketrampilan menyimak cerita belum berjalan secara optimal. Hal ini dapat dilihat dari setiap pembelajaran guru masih menggunakan metode ceramah pada saat pembelajaran berlangsung. Sehingga siswa terlihat kurang antusias dan cenderung pasif karena proses pembelajaran bersifat monoton dan membosankan.

Penggunaan media audio visual dalam pembelajaran sangat memungkinkan untuk meningkatkan kemam-puan berfikir yang diharapkan. Melalui media audio visual diharapkan ada peningkatan dalam proses pembe-lajaran bahasa Indonesia, terutama dalam hal menyimak cerita dan peningkatan prestasi siswa. Berda-sarkan studi lapangan tersebut pengembang tertarik untuk mengembangkan media audio visual mata pelajaran Bahasa Indonesia untuk sekolah dasar.

\section{B. KAJIAN PUSTAKA Pengembangan}

Pengembangan adalah proses penerjemahan spesifikasi desain ke dalam bentuk fisik. ${ }^{3}$ Kawasan pengembangan

2 Daniel Goleman, Working With Emotional Intelligence, trans. oleh Alex Kantjono W (Jakarta: Gramedia Pustaka Utama, 2002).

${ }^{3}$ B. Seels Barbara dan Rita C. Richey, Teknologi Pembelajaran: Definisi dan Kawasannya, trans. 
dapat diorganisasikan dalam empat kategori antara lain teknologi cetak, teknologi audio visual, teknologi berbasis komputer, dan teknologi terpadu. Pengembangan adalah suatu proses mendesain pembelajaran secara logis, dan sistematis dalam rangka untuk menetapkan segala sesuatu yang akan dilaksanakan dalam proses kegiatan belajar dengan memperhatikan potensi dan kompetensi siswa. ${ }^{4}$

\section{Model Pengembangan}

Pengembangan ini menggunakan model rancangan pembelajaran Dick and Carey. ${ }^{5}$ Model pembelajaran ini merupakan salah satau model desain pembelajaran yang berfokus pada sistem pembelajaran dan memberikan langkahlangkah pengembangan bahan pembelajaran. $^{6}$ Di dalam rancangan model Dick and Carey pengembangan dan pemilihan bahan pembelajaran diuraikan pada langkah ke-7. Pedoman pemilihan bahan pembelajaran untuk pembelajaran adalah agar membe-lajarkan pembelajar. Sarana pendukung ini harus dapat memberikan motivasi dan mudah dipelajari oleh siswa. ${ }^{7}$

\section{Media Audio Visual}

oleh Dewi S Prawiradilaga (Jakarta: Universitas Negeri Jakarta, 1994).

4 Abdul Majid, Perencanaan Pembelajaran Mengembangkan Sstandar Kompetensi Guru (Bandung: Remaja Rosdakarya, 2008).

5 Walter Dick, Lou Carey, dan James O. Carey, The systematic design of instruction (Pearson Higher Ed, 2014).

6 Tjeerd Plomp dan Donald P. Ely, International encyclopedia of educational technology (ERIC, 1996).

${ }^{7}$ Atwi Suparman dan Atwi Suparman, "Desain instruksional," 2015.
1. Pengertian Media Audio Visual

Media merupakan salah satu bentuk sumber belajar/komponen sistem instruksional yaitu berupa bahan. Hal ini seperti tercantum dalam kawasan Teknologi Pendidi-kan/Instructional. Paradigma tahun 1994 media video termasuk pada audiovisual technologies. ${ }^{8}$ Media video merupakan media audiovisual atau jenis media pandang-dengar yang menampilkan informasi dalam bentuk moving image (citra bergerak). ${ }^{9}$

Media audio visual memiliki kemampuan untuk memperluas wawasan pengetahuan pemirsa dengan menampilkan informasi dan pengetahuan baru dan pengalaman yang sulit diperoleh langsung oleh pemirsa. Media ini mampu merangsang minat belajar pemirsa melalui penyajian gambar dan informasi yang menarik. Pengguaan media audio visual dalam proses belajar akan mampu mengarahkan terjadinya respon tertentu dari pemirsa sesuai dengan yang diharapkan.

2. Tujuan Media Audio Visual

a. Memperjelas dan mempermudah penyajian pesan agar tidak terlalu bersifat verbalis

b. Mengatasi keterbatasan waktu, ruang, dan daya indera siswa maupun guru

c. Meningkatkan motivasi dan gairah belajar siswa untuk menguasai mata pelajaran secara utuh

\footnotetext{
8 Barbara dan Richey, Teknologi Pembelajaran: Definisi dan Kawasannya.

${ }^{9}$ Dewan Film Nasional, Rumusan Hasil Seminar Pengelolaan Teknologi Video Untuk Pembangunan (Jakarta: Dewan Film Nasional, 1981).
} 
d. Mengembangkan kemampuan siswa dalam berinteraksi langsung dengan lingkungan

e. Memungkinkan siswa untuk belajar lebih bermakna dengan tayangantanyang yang jelas dan menarik perhatian siswa

f. Memungkinkan siswa untuk melakukan kegiatan peniruan sesuai dengan isi tayangan yang terdapat dalam video pembelajaran.

3. Kelebihan dan keterbatasan media audio visual

Media audio visual untuk keperluan pembelajaran memiliki beberapa kelebihan dan keterbatasan antara lain:

a. Kelebihan

1) dapat menarik perhatian untuk periode-periode yang singkat dari rangsangan luar lainnya

2) dengan alat perekam lainnya pita video sejumlah besar penonton dapat memperoleh informasi dari ahli-ahli atau spesialis

3) demonstrasi yang sulit direkam sebelumnya, sehingga pada waktu mengajar guru bisa memusatkan perhatian pada menyajiannya

4) keras lemah suara yang ada bisa diatur dan disesuaikan bila akan disisipi komentar yang akan didengar

5) gambar proyeksi bisa di "beku" kan untuk diamati dengan sesama. Guru bisa mengatur dimana dia akan mengatur gerakan gambar tersebut ; kontrol sepenuhnya ada di tangan guru

6) ruangan tidak perlu digelapkan untuk penyajiannya.

b. Keterbatasan
1) perhatian penonton sulit dikuasai, partisipasi mereka jarang di praktekkan

2) sifat komukasinya bersifat satu arah dan harus diimbangi dengan pencarian bentuk umpan balik yang lain

3) kurang mampu menampilkan detail dari objek yang disajian secara sempurna

4) memerlukan peralatan yang mahal dan kompleks. ${ }^{10}$

4. Unsur-unsur media audio visual

a. Unsur gambar

1) Pemain/obyek selain gambar manusia dan benda dapat pula berupa grafis

2) Setting lingkungan/tempat dimana obyek berada

3) Property benda-benda yang mengikuti/melekat pada obyek dan setting yang dapat dipindah-pindah misalnya pakaian, aksesoris dsb.

4) Lighting dengan pencahayaan obyek dapat terlihat, pencahayaan dapat memberi kesan suasana dan artistik dalam cerita

b. Unsur suara

1) Suara manusia melalui dialog dan monolog

2) Musik dalam program video/tv

3) Penggunaan musik dan sound effect. ${ }^{11}$

5. Penulisan naskah

Penulisan naskah secara teoritis merupakan komponen dari

\footnotetext{
${ }^{10}$ Arief S. Sadiman, Media Pendidikan: Pengertian, Pengembangan, dan Pemanfaatannya (Jakarta: Raja Grafindo Persada, 2009).

${ }^{11}$ Andi Prastowo, Panduan Kreatif Membuat Bahan Ajar Inovatif (Yogyakarta: Diva Press, 2011).
} 
pengembangan media. Secara lebih praktis, hal tersebut merupakan bagian dari serangkain kegiatan produksi media melalui tahap-tahap perencanaan dan desain, pengembangan, serta evaluasi. Tahap-tahap kegiatan tersebut adalah:
a. Sinopsis
b. Treatment
c. Storyboard
d. Skrip atau naskah
e. Skenario. ${ }^{12}$

\section{Pembelajaran Bahasa Indonesia}

Pembelajaran Bahasa Indonesia merupakan mata pelajaran mendasar yang sudah diajarkan sejak pendidikan rendah sampai perguruan tinggi. Bahasa Indonesia mempunyai peranan penting dalam proses pembelajaran. Kurikulum Bahasa Indonesia di sekolah dasar mempunyai karakteristik antara lain :

1. Menggunakan pendekatan komunikatif ketampilan proses, tematis integrative, dan lintas kurikulum.

2. Mengutamakan variasi, kealamian kebermaknaan fleksibilitas.

3. Penggunaan metode.

4. Memberi peluang untuk menggunakan berbagai sumber belajar. ${ }^{13}$

Standar kompetensi mata pelajaran Bahasa Indonesia bersumber pada hakikat pembelajaran Bahasa yaitu belajar Bahasa (belajar komunikasi) dan belajar sastra (belajar menghargai manusia dan nilai-nilai kemanusiaannya). Oleh karena itu, pelajaran Bahasa Indonesia mengupayakan

12 Sadiman, Media Pendidikan: Pengertian, Pengembangan, dan Pemanfaatannya.

13 Dadan Djuanda, Pembelajaran Bahasa Indonesia yang Komunikatif dan Menyenangkan (Jakarta: Depdiknas, 2006). peningkatan kemampuan siswa untuk berkomunikasi secara lisan dan tertulis serta menghargai karya cipta bangsa Indonesia.

\section{METODE PENELITIAN}

Pengembangan media audio visual mata pelajaran Bahasa Indonesia kelas 3 semester 2 menggunakan model rancangan pembelajaran Dick dan Carey. ${ }^{14}$ Pengembangan media audio visual ini dikembangkan dengan mengikuti model desain Dick dan Carey yang telah dimodivikasi berdasarkan keperluan pengembangan. Model ini memiliki sepuluh langkah prosedural, hanya saja untuk pengembangan ini diadaptasi menjadi sembilan langkah, yakni: (1) mengidentifikasi tujuan umum pembelajaran (2) analisis pembelajaran (3) mengidentifikasi karakteristik siswa (4) merumuskan tujuan khusus pembelajaran (5) mengembangkan instrumen penilaian (6) mengembangkan strategi pembelajaran mengembangkan dan memilih bahan pembelajaran (8) merancang dan melaksanakan evaluasi formatif (9) merevisi produk pembelajaran.

Prosedur yang ditempuh dalam pengembangan ini adalah:

1. Identifikasi Tujuan Umum
Pembelajaran
Langkah awal adalah menganalisis kebutuhan untuk pemecahan masalah pembelajaran yang ada dengan melakukan observasi terhadap kesesuaian media audio visual dengan karakteristik mata pelajaran,

${ }^{14}$ Dick, Carey, dan Carey, The systematic design of instruction. 
karakteristik siswa, serta kurikulum yang dikembangkan. Selanjutnya melakukan identifikasi tujuan umum pembelajaran, yaitu menentukan apa yang akan dilakukan siswa setelah selesai mengikuti pembelajaran. Mengidentifikasi tujuan umum pembelajaran ini dilakukan untuk mendapatkan gambaran tentang kualifikasi kemampuan yang diharapkan dan dapat dimiliki siswa setelah mengikuti pembelajaran.

\section{Analisis Pembelajaran}

Analisis pembelajaran terhadap tujuan umum dapat dilakukan melalui dua tahap:

a. Menggolongkan pernyataan tujuan umum menurut jenis kapabilitas belajar yang dikemukakan oleh Gagne mengenai informasi verbal, ketrampilan intelektual, strategi kognitif, sikap, dan psikomotor.

b. Menggunakan analisis pengalihan informasi dengan mendeskripsikan secara tepat apa yang akan dikerjakan siswa untuk mencapai tujuan pembelajaran.

\section{Identifikasi Karakteirstik Siswa}

Hal ini dilakukan untuk mengetahui karakteristik siswa sekolah dasar untuk dipertimbangkan dalam merancang kegiatan pembelajaran yang dapat diperoleh melalui observasi. Karakteristik siswa yang berkaitan dengan kemampuan awal yang telah dipelajari berguna sebagai pijakan dalam pemilihan strateri pengajaran yang optimal. ${ }^{15}$

\footnotetext{
15 Hamzah B. Uno, Nina Lamatenggo, dan Satria Koni, Desain Pembelajaran (Bandung: MSQ Publishing, 2010).
}

4. Merumuskan Tujuan Pembelajaran Khusus

Guru menyusun pernyataaan spesifik tentang apa yang bisa dilakukan dalam menyelesaikan pembelajaran. Pernyataan yang dijabarkan dari keterampilan yang dikenali dengan cara melakukan analisis pembelajaran dengan menyebutkan analisis pembelajaran dengan menyebutkan keterampilan yang dipelajari. Perumusan tujuan khusus pembelajaran didasarkan hasil analisis pembelajaran terhadap 7 rumusan tujuan umum pembelajaran serta identifikasi karakteristik dan kemampuan awal siswa.

\section{Mengembangkan Instrumen Penilaian} Instrumen penilaian merupakan komponen yang digunakan sebagai alat untuk mengukur seberapa jauh tingkat keberhasilan siswa dalam mencapai tujuan pembelajaran khusus. Hasil pencapaian siswa ini merupakan petunjuk akan tingkat keberhasilan sistem pembelajaran yang digunakan. ${ }^{16}$

\section{Mengembangkan}

Pembelajaran

Pada tahap ini dilakukan pemilihan strategi pembelajaran yang sesuai dengan tujuan pembelajaran. Strategi pembelajaran yang dipilih harus dalam bentuk demonstrasi yang melibatkan pertisipasi aktif siswa. Maka dalam media audio visual yang dikembangkan menggunakan model Dick dan Carey ini menggunakan pendekatan pembelajaran kontekstual, dimana dalam strategi

\footnotetext{
16 Badan Standar Nasional Pendidikan, "Standar Isi dan Kompetensi Lulusan” (Depdiknas, 2007).
} 
pembelajaran ini pertisipasi aktif siswa sangat diutamakan.

7. Mengembangkan dan Memilih Bahan Pembelajaran

Dalam pengembangan dan pemilihan bahan pembelajaran Dick dan Carey menganjurkan agar bahan/material pengajaran merupakan bahan pengajaran yang dapat dipelajari sendiri oleh siswa.

a. Pemilihan media

1) Karakteristik isi pembelajaran dengan konstruk isi berupa fakta maupun konsep

2) Menguraikan pemilihan media video untuk tujuan pembelajaran dari aspek kognitif, afektif, dan psikomotor. ${ }^{17}$

b. Pengembangan progam media audio visual

Memproduksi media audio visual penulisan naskah merupakan kegiatan untuk mewujudkan gagasan menjadi program media audio visual. Naskah merupakan persyaratan yang harus ada untuk suatu program terkontrol isi dan bentuk sajiannya. Tahap-tahap kegiatan tersebut adalah:
1) Sinopsis
2) Treatment
3) Storyboard
4) Skrip atau naskah
5) Skenario
6) Produksi program video. ${ }^{18}$

8. Merancang dan Melaksanakan Evaluasi Formatif

a. Desain Uji Coba

\footnotetext{
17 Ronald H. Anderson, Pemilihan dan pengembangan media untuk pembelajaran (Jakarta: Rajawali, 1987).

${ }^{18}$ Sadiman, Media Pendidikan: Pengertian, Pengembangan, dan Pemanfaatannya.
}

Pada dasarnya kegiatan uji coba produk pengembangan dilaksanakan sebagai langkah evaluasi formatif yang terdiri atas 1) desain uji coba, 2) subyek uji coba, 3) jenis data, 4) instrument pengumpulan data, dan 5) teknik analisis data

b. Subyek Uji Coba

1. Ahli isi/materi

a) Merupakan guru mata pelajaran Bahasa Indonesia

b) Memiliki latar belakang minimal S1.

c) Menguasai materi yang berkaitan dengan mata pelajaran

2. Ahli media

a) Merupakan dosen dari jurusan Teknologi Pendidikan atau Teknologi Pembelajaran

b) Memiliki latar belakang pendidikan minimal S2

c) Memiliki keahlian tentang media pembelajaran

3. Uji coba sasaran

Uji coba sasaran yang dimaksud adalah sasaran pengguna produk pengembangan yaitu siswa kelas 3 SDN Kiping 1.

c. Jenis Data

Jenis data yang diperoleh berdasarkan uji coba media audio visual ini berupa data kuantitatif dan kualitatif. Data kuantitatif diperoleh dari angket yang disebarkan kapada subyek uji coba, sedangkan data kualitatif berupa komentar, tanggapan dan saran-saran perbaikan.

d. Instrumen Pengumpulan Data

1. Observasi dilakukan untuk memperoleh informasi tentang aktivitas guru dan siswa selama kegiatan pelajaran berlangsung. Aspek yang diobservasi meliputi, aktivitas 
guru, aktivitas siswa, interaksi antara guru dan siswa, sehingga dapat mengidentifikasi masalah yang perlu dipecahkan.

2. Angket, digunakan untuk mengumpulkan data tentang keefektifan, efisiensi, dan kemenarikan produk media audio visual pada kegiatan uji coba lapangan.

3. Wawancara, pedoman ini digunakan dalam rangka untuk mengumpulkan data identifikasi masalah, penyelidikan kontekstual serta kegiatan uji coba lapangan khususnya untuk saran dan masukan.

4. Dokumentasi, digunakan untuk memperoleh atau mendapatkan informasi tentang silabus, RPP (Rencana Pelaksanaan Pembelajaran) dan latar belakang mahasiswa.

e. Teknik Analisis Data

Data yang telah terkumpul dari penilaian ahli media, ahli materi dan audiens (siswa) yang berupa angket akan diolah untuk untuk merevisi media audio visual tersebut.

\section{f. Desiminasi}

Setelah kegiatan pengembangan media audio visual selesai, kegiatan dilanjutkan dengan memfokuskan pada desiminasi.

\section{Merevisi Produk Pembelajaran}

Data yang diperoleh dari evaluasi formatif dikumpulkan dan di interpretasikan untuk memecahkan kesulitan yang dihadapi siswa dalam mencapai tujuan pembelajaran, dengan kata lain evaluasi ini digunakan untuk merevisi media audio visual agar lebih efektif.

\section{HASIL DAN PEMBAHASAN}

1. Uji Ahli Isi/Materi

Data yang diperoleh dari ahli isi berupa data kualitatif dalam bentuk angket komentar dan saran terhadap media audio visual. Aspek-aspek yang dinilai antara lain sebagai berikut :

1) Kejelasan materi dalam mata pelajaran Bahasa Indonesia menggunakan media audio visual

2) Kelengkapan materi dalam mata pelajaran Bahasa Indonesia pada media audio visual

3) Kesesuaian media audio visual dengan materi pelajaran

4) Kejelasan gambar dan narasi dalam media audio visual

5) Kecepatan siswa memahami materi dalam pelajaran Bahasa Indonesia jika menggunakan media audio visual

6) Efisiensi pembelajaran dengan menggunakan media audio visual pada mata pelajaran Bahasa Indonesia

7) Ketepatan penggunaan media audio visual pada pelajaran Bahasa Indonesia

8) Kecenderungan siswa untuk belajar lagi (menandakan siswa tidak bosan/jenuh)

9) Daya tarik materi yang terdapat dalam mata pelajaran Bahasa Indonesia

10) Penggunaan LKS sebagai penyerta sesuai untuk membantu siswa dalam belajar.

Berdasarkan hasil analisis data ahli materi diperoleh hasil 94,6\%, sehingga dapat diinterpretasikan bahwa media audio visual yang dikembangkan termasuk dalam kriteria valid/layak untuk digunakan dalam proses pembelajaran. 


\section{Uji Ahli Media}

Data yang diperoleh dari hasil validasi ahli media pembelajaran adalah berupa data kuantitatif (data angka) dan data kualitatif (data saran atau masukan) terhadap produk media audio visual. Berikut dijabarkan komponen-komponen yang dinilai oleh ahli media pembelajaran tersebut:

1) Kesesuaian pemilihan media audio visual ini dengan materi yang disajikan

2) Kesesuaian media audio visual ini untuk mencapai tujuan pembelajaran yang akan dicapai

3) Kemenarikan dalam penyajian gambar video/animasi pada media audio visual

4) Kejelasan gambar dalam media audio visual

5) Kejelasan teks dalam media audio visual ini untuk dipahami

6) Narasi dalam media audio visual untuk dipahami

7) Kesesuaian gambar dan narasi terhadap tujuan pembelajaran

8) Penggunaan warna secara keseluruhan pada media audio visual

9) Kejelasan dari pesan gam-bar/animasi dalam media audio visual

10) Penggunaan LKS sebagai penyerta sesuai untuk membantu siswa dalam belajar

Berdasarkan hasil analisis data ahli media diperoleh hasil 95\%, sehingga dapat diinterpretasikan bahwa media audio visual yang dikembangkan termasuk dalam kriteria valid/layak untuk digunakan dalam proses pembelajaran.

3. Uji Coba Perseorangan

Uji coba perseorangan pada pengembangan video pembelajaran dilakukan pada 2 siswa. Uji coba perseorangan ini digunakan untuk mengidentifikasi kekurangan-kekurangan yang tidak terdeteksi pada saat pembuatan produk. Aspek-aspek yang dinilai antara lain sebagai berikut :

1) Kejelasan materi yang disampaikan dalam media audio visual

2) Isi materi dalam media audio visual

3) Senang belajar menggunakan media audio visual

4) Kejelasan gambar dan teks yang disajikan dalam media audio visual

5) Kemenarikan gambar yang disajikan dalam media audio visual

6) Belajar dengan media audio visual ini memberikan motivasi mengikuti pelajaran

7) Perasaan siswa setelah belajar menggunakan media audio visual

8) Dengan bantuan media audio ono siswa lebih mudah memahami materi

9) Kemenarikan belajar dengan media audio visual

10) Kemudahan LKS untuk dikerjakan oleh siswa

Berdasarkan hasil analisis data siswa pada uji coba perseorangan diperoleh hasil 90,8\%, sehingga dapat disimpulkan bahwa media audio visual yang dikembangkan termasuk dalam kriteria valid/layak untuk digunakan dalam proses pembelajaran.

\section{Uji Coba Kelompok Kecil}

Uji coba kelompok kecil ini bertujuan untuk melihat sejauh mana strategi penyampaian pembelajaran yang dikembangkan dalam bentuk media audio visual dapat mempermudah dan memotifasi siswa dalam belajar. Serta 
mengidentifikasi kekurangan-kekurangan yang tidak terdeteksi pada uji coba perorangan dan meninjau kembali revisi atau perbaikan yang dilakukan pengembang. Berdasarkan hasil analisis data siswa pada uji coba kelompok kecil diperoleh hasil 91\%, sehingga dapat disimpulkan bahwa media audio visual yang dikembangkan termasuk dalam kriteria valid/layak untuk digunakan dalam proses pembelajaran secara kelompok.

5. Uji Coba Kelompok Besar (Uji Lapangan)

Uji coba kelompok besar ini bertujuan untuk melihat sejauh mana strategi penyampaian pembelajaran yang dikembangkan dalam bentuk media audio visual dapat memudahkan dan memotivasi siswa dalam belajar. Serta mengidentifikasi kekurangan-kekurangan yang tidak terdeteksi pada uji coba kelompok kecil dan meninjau kembali revisi atau perbaikan yang dilakukan pengembang. Berdasarkan hasil analisis data ahli siswa pada uji coba kelompok besar/klasikal diperoleh hasil 90,8\%, sehingga dapat disimpulkan bahwa media audio visual yang dikembangkan termasuk dalam kriteria valid/layak untuk digunakan dalam proses pembelajaran secara klasikal.

\section{PENUTUP}

\section{Simpulan}

Pengembang melakukan pengembangan produk berupa media audio visual ini sebagai salah satu bentuk strategi penyampaian pasan pembelajaran untuk meningkatkan kemampuan strategi mengajar guru. Dalam mengajarkan materi guru mengalami beberapa kendala pada saat ingin memberikan pembelajaran kontekstual dikarenakan adanya keterbatasan dalam ruang dan waktu, dengan produk ini siswa akan lebih mudah memahami materi, lebih cepat memahami materi, dan lebih termotivasi untuk belajar.

Dari hasil penelitian yang telah dilakukan pengembang, maka media audio visual ini telah berhasil diuji tingkat efektivitasnya. Dimana dari penelitian tersebut pengembang telah mendapatkan data yang mendukung bahwa produk yang dikembangkan telah memiliki nilai efektifitas dan daya tarik untuk digunakan dalam pembelajaran. Hal ini tentu menunjukkan bahwa media audio visual telah memenuhi kebutuhan guru dalam meningkatkan strategi penyampaian pesan pembelajaran dan telah memenuhi kebutuhan siswa yang beragam dalam mempelajari materimateri yang ada.

\section{E. DAFTAR PUSTAKA}

Anderson, Ronald H. Pemilihan dan pengembangan media untuk pembelajaran. Jakarta: Rajawali, 1987.

Barbara, B. Seels, dan Rita C. Richey. Teknologi Pembelajaran: Definisi dan Kawasannya. Diterjemahkan oleh Dewi S Prawiradilaga. Jakarta: Universitas Negeri Jakarta, 1994.

Dewan Film Nasional. Rumusan Hasil Seminar Pengelolaan Teknologi Video Untuk Pembangunan. Jakarta: Dewan Film Nasional, 1981. 
Dick, Walter, Lou Carey, dan James 0.

Carey. The systematic design of instruction. Pearson Higher Ed, 2014.

Djuanda, Dadan. Pembelajaran Bahasa Indonesia yang Komunikatif dan Menyenangkan. Jakarta:

Depdiknas, 2006.

Goleman, Daniel. Working With Emotional Intelligence. Diterjemahkan oleh Alex Kantjono W. Jakarta: Gramedia Pustaka Utama, 2002.

Majid, Abdul. Perencanaan Pembelajaran Mengembangkan Sstandar Kompetensi Guru. Bandung: Remaja Rosdakarya, 2008.

Pendidikan, Badan Standar Nasional. "Standar Isi dan Kompetensi Lulusan." Depdiknas, 2007.

Plomp, Tjeerd, dan Donald P. Ely. International encyclopedia of educational technology. ERIC, 1996.

Prastowo, Andi. Panduan Kreatif Membuat Bahan Ajar Inovatif. Yogyakarta: Diva Press, 2011.

Sadiman, Arief S. Media Pendidikan: Pengertian, Pengembangan, dan Pemanfaatannya. Jakarta: Raja Grafindo Persada, 2009.

Setyosari, Punaji, dan Sihkabuden. Media Pembelajaran. Malang: Elang Mas, 2005.

Suparman, Atwi, dan Atwi Suparman.

"Desain instruksional," 2015.

Uno, Hamzah B., Nina Lamatenggo, dan

Satria Koni. Desain Pembelajaran.

Bandung: MSQ Publishing, 2010. 
70| ibriez | Iurnal Kependidikn Dasar Islam Bertasis Sains $\mid$ Vol 2 No 2 Tahun 2017 